\title{
Association of the TRIB1 tribbles homolog 1 gene rs17321515 A>G polymorphism and serum lipid levels in the Mulao and Han populations
}

Lynn Htet Htet Aung ${ }^{1}$, Rui-Xing Yin ${ }^{*}$, Dong-Feng Wu' ${ }^{1}$, Qing Li ${ }^{1}$, Ting-Ting Yan ${ }^{1}$, Yi-Ming Wang ${ }^{2}$, Hui Li ${ }^{3}$, Dai-Xun Wei ${ }^{4}$, Yuan-Lu Shi ${ }^{4}$ and De-Zhai Yang ${ }^{5}$

\begin{abstract}
Background: The association of rs17321515 single nucleotide polymorphism (SNP) near TRIB1 gene and serum lipid profiles has never been studied in the Chinese population. Therefore, the present study was undertaken to detect the association of rs17321515 SNP and several environmental factors on serum lipid levels in the Mulao and Han populations.

Methods: A total of 639 unrelated subjects of Mulao nationality and 644 participants of Han nationality were randomly selected from our previous stratified randomized cluster samples. Genotypes of the TRIB1 rs17321515 A $>$ G SNP were determined via polymerase chain reaction and restriction fragment length polymorphism, and then confirmed by direct sequencing.

Results: Serum apolipoprotein (Apo) B levels were higher in Mulao than in Han $(P<0.05)$. There were no differences in the genotypic and allelic frequencies between the two ethnic groups $(P>0.05)$. High- and lowdensity lipoprotein cholesterol (HDL-C and LDL-C) levels in Han were different among the genotypes $(P<0.05$ for each), the subjects with AG/GG genotypes had higher HDL-C and LDL-C levels than the subjects with AA genotype. Total cholesterol (TC), HDL-C, LDL-C, ApoA1 and ApoB levels in Han males were different among the genotypes $(P<0.05-0.001)$, the $\mathrm{G}$ carriers had higher TC, HDL-C, LDL-C, ApoA1 and ApoB levels than the $\mathrm{G}$ noncarriers. HDL-C levels in Mulao males were different among the genotypes $(P<0.05)$, the $\mathrm{G}$ carriers had lower $\mathrm{HDL}-\mathrm{C}$ levels than the G noncarriers. Serum HDL-C and LDL-C levels in both ethnic groups and TG levels in Han were correlated with the genotypes or alleles $(P<0.05-0.01)$. TG and HDL-C levels in Mulao males and TG, HDL-C, LDL-C and ApoA1 levels in Han males were correlated with genotypes or alleles $(P<0.05-0.001)$. TG and ApoA1 levels in Han females were associated with genotypes $(P<0.05$ for each). Serum lipid parameters were also associated with several environmental factors in both ethnic groups.
\end{abstract}

Conclusions: The associations of TRIB1 rs17321515 SNP and serum lipid levels are different between the Mulao and Han populations. These discrepancies might partly result from different TRIB1 gene-environmental interactions in both ethnic groups.

\section{Introduction}

Over decades, it has evident that the most attributable and heritable risk factor for coronary artery disease (CAD) is the unfavorable serum lipid profile such as elevated serum levels of total cholesterol (TC) [1], triglyceride (TG) [2],

\footnotetext{
* Correspondence: yinruixing@yahoo.com.cn

'Department of Cardiology, Institute of Cardiovascular Diseases, the First Affiliated Hospital, Guangxi Medical University, 22 Shuangyong Road,

Nanning 530021, Guangxi, People's Republic of China

Full list of author information is available at the end of the article
}

low-density lipoprotein cholesterol (LDL-C) [3], and apolipoprotein (Apo) B [4], or low levels of high-density lipoprotein cholesterol (HDL-C) [5] and ApoA1 [4]. As a result, serum lipid level is the major modifiable risk factor for $\mathrm{CAD}$ and also the main target for therapeutic intervention [6]. Disorders of lipid metabolism are well recognized as a complex trait caused by multiple environmental and genetic factors [7-9] and their interactions [10,11]. It is well known that almost $40-60 \%$ of the inter-individual 
variation in plasma lipid phenotypes can be explained by genetic polymorphisms [12-14].

It is noticeable that through genome-wide association studies, a growing number of new loci involving in lipid metabolism have been identified [15-17]. The Tribbles, drosophila, Homolog of, 1 (TRIB1) (http://www.ncbi.nlm. nih.gov/gene) is one of the potential candidate genes that play a substantial role in the cholesterol metabolism and the atherosclerosis process [18-20]. It is located on chromosome 8q24 $[15,17,21]$ and encodes the protein tribbles homolog 1 , which is a member of the recently identified tribbles protein family, governing as an adaptor or scaffold protein [22]. One study demonstrating the role of TRIB1 in lipoprotein metabolism in mice reported that TRIB1 overexpression significantly reduced the plasma levels of very low-density lipoprotein (VLDL), LDL-C, HDL-C and TG; TRIB1 deficiency experienced the reverse effects on plasma cholesterol and TG in vise versa [23]. Recently, a common single nucleotide polymorphism (SNP) adjacent to the TRIB1 gene locus namely rs17321515 is a very compelling SNP effecting lipoprotein metabolism. The minor allele at this SNP was found to be associated with an atheroprotective lipid phenotype of lower TG and LDL-C, and higher HDL-C resulting in a significantly reduced risk of CAD in European [7], Malays and Asian Indians [24]. This association was also genome-wide significant in severe hypertriglyceridemic subjects [25]. However, the effect of this SNP on serum lipid levels was not functionally validated and the mechanism was yet unclear. Furthermore, the reproducibility of this association has not been detected in the Chinese population so far.

Among a total of 56 ethnic groups in China, Han is the largest one. Mulao (also known as Mulam) is one of the minorities with a population of 207,352 according to the fifth national census statistics of China in 2000. Ninety percent of them live in the Luocheng Mulao Autonomous County, Guangxi Zhuang Autonomous Region. They call themselves "Ling" and a smaller group call themselves "Jin" or "Bendiren". Historical data show that the history of this ethnic minority can be traced back to the Jin Dynasty (AD 265-420). It is believed that the Mulao people are the descendants of the ancient Baiyue tribe in south China and ethnically related to the neighboring ethnic groups. One previous study has shown that the genetic relationship between Mulao nationality and other minorities in Guangxi was much closer than that between Mulao and Han or Uighur nationality [26]. In a previous study, we have shown a significant association of UDP-N-acetylalpha-D-galactosamine: polypeptide $\mathrm{N}$-acetylgalactosaminyltransferase 2 gene (GALNT2) polymorphisms and serum lipid levels in the Mulao population [27]. To the best of our knowledge, however, no prior study has been conducted about the association of rs17321515 SNP and serum lipid levels in the Chinese population. Therefore, the aim of the present study was to assess the association of TRIB1 gene rs17321515 SNP and several environmental factors with serum lipid phenotypes in the Mulao and Han populations.

\section{Materials and methods Study population}

A total of 639 unrelated subjects of Mulao nationality comprising 301 males (47.1\%) and 338 females (52.9\%) and 644 unrelated participants of Han nationality including 299 men (46.4\%) and 345 women (53.6\%) were randomly selected from our previous stratified randomized cluster samples. All of them were rural agricultural workers residing in Luocheng Mulao Autonomous County, Guangxi Zhuang Autonomous Region, People's Republic of China. The age range was from 15 to 80 years. The mean age of Mulao participants was $53.11 \pm$ 14.97 years, whereas that of Han subjects was $53.32 \pm$ 15.14 years. All participants were essentially healthy and had no evidence of diseases related to atherosclerosis, $\mathrm{CAD}$ and diabetes. Any participant had a history of taking medications known to affect serum lipid levels (lipid-lowering drugs such as statins or fibrates, betablockers, diuretics, or hormones) was excluded before the blood sample was taken. The study design was approved by the Ethics Committee of the First Affiliated Hospital, Guangxi Medical University. Informed consent was obtained from all participants.

\section{Epidemiological survey}

The survey was carried out using internationally standardized methods, following a common protocol [28]. Information on demographics, socioeconomic status, and lifestyle factors was collected with standardized questionnaires. The intake of alcohol was quantified as the number of liangs (about $50 \mathrm{~g}$ ) of rice wine, corn wine, rum, beer, or liquor consumed during the preceding 12 months. Alcohol consumption was categorized into groups of grams of alcohol per day: $<25$ and $\geq 25$. Smoking status was categorized into groups of cigarettes per day: $<20$ and $\geq 20$. In the physical examination, several parameters such as height, weight, and waist circumference were measured. Sitting blood pressure was measured three times with the use of a mercury sphygmomanometer after a 5-minute of rest, and the average of the three measurements was recorded. Systolic blood pressure was determined by the first Korotkoff sound, and diastolic blood pressure by the fifth Korotkoff sound. Body weight, to the nearest 50 grams, was measured using a portable balance scale. Subjects were weighed in a minimum of clothing with shoes off. Height was measured, to the nearest $0.5 \mathrm{~cm}$, using a stadiometer. From these two measurements body mass index $\left(\mathrm{BMI}, \mathrm{kg} / \mathrm{m}^{2}\right)$ was calculated. 


\section{Biochemical measurements}

A venous blood sample of $5 \mathrm{~mL}$ was obtained from all subjects after at least 12 hours of fasting. A two fifth of the sample $(2 \mathrm{~mL})$ was collected into glass tubes and used to determine serum lipid levels. The remaining three fifth of the sample $(3 \mathrm{~mL})$ was transferred to the tubes contained anticoagulants $(4.80 \mathrm{~g} / \mathrm{L}$ citric acid, $14.70 \mathrm{~g} / \mathrm{L}$ glucose, and $13.20 \mathrm{~g} / \mathrm{L}$ tri-sodium citrate) and was used to extract deoxyribonucleic acid (DNA). Measurements of serum TC, TG, HDL-C, and LDL-C levels in the samples were performed by enzymatic methods with commercially available kits (RANDOX Laboratories Ltd., Ardmore, Diamond Road, Crumlin Co. Antrim, United Kingdom, BT29 4QY; Daiichi Pure Chemicals Co., Ltd., Tokyo, Japan). Serum ApoA1 and ApoB levels were detected by the immunoturbidimetric immunoassay using a commercial kit (RANDOX Laboratories Ltd.). All determinations were performed with an autoanalyzer (Type 7170A; Hitachi Ltd., Tokyo, Japan) in the Clinical Science Experiment Center of the First Affiliated Hospital, Guangxi Medical University [29,30].

\section{DNA amplification and genotyping}

Genomic DNA was isolated from peripheral blood leukocytes using the phenol-chloroform method [31,32]. The extracted DNA was stored at $4^{\circ} \mathrm{C}$ until analysis. Genotyping of the TRIB1 rs17321515 SNP was performed by polymerase chain reaction and restriction fragment length polymorphism (PCR-RFLP). PCR amplification was performed using 5'-AGTGCAGCAAAGTGGAAAGAG-3' and 5'-AGAGCGAGACTGTCACACACA-3' (Sangon, Shanghai, People's Republic of China) as the forward and reverse primer pairs; respectively. Each amplification reaction was performed in a total volume of $25 \mathrm{~mL}$, containing $10 \times$ PCR buffer $\left(1.8 \mathrm{mM} \mathrm{MgCl}_{2}\right) 2.5 \mu \mathrm{L}, 1 \mathrm{U}$ Taq polymerase, $2.5 \mathrm{mmol} / \mathrm{L}$ of each dNTP (Tiangen, Beijing, People's Republic of China) $2.0 \mu \mathrm{L}, 20 \mathrm{pmol} / \mathrm{L}$ of each primer and $50 \mathrm{ng}$ of genomic DNA, processing started with $95^{\circ} \mathrm{C}$ for $5 \mathrm{~min}$ and followed by $45 \mathrm{~s}$ of denaturing at $94{ }^{\circ} \mathrm{C}, 45 \mathrm{~s}$ of annealing at $60{ }^{\circ} \mathrm{C}$ and $1 \mathrm{~min}$ of elongation at $72{ }^{\circ} \mathrm{C}$ for 33 cycles. The amplification was completed by a final extension at $72{ }^{\circ} \mathrm{C}$ for $7 \mathrm{~min}$. Then $10 \mathrm{U}$ of Eco130I (StyI) enzyme was added directly to the PCR products $(10 \mu \mathrm{L})$ and digested at $37{ }^{\circ} \mathrm{C}$ overnight. After restriction enzyme digestion of the amplified DNA, genotypes were identified by electrophoresis on $2 \%$ ethidium-bromide stained agarose gels and visualizing with ultraviolet illumination. Genotypes were scored by an experienced reader blinded to the epidemiological and lipid results. Twelve samples (AA, AG and GG genotypes in four; respectively) detected by the PCR-RFLP were also confirmed by direct sequencing. The PCR product was purified by low melting point gel electrophoresis and phenol extraction, and then the DNA sequences were analyzed in Shanghai Sangon Biological
Engineering Technology \& Services Co., Ltd., People’s Republic of China.

\section{Diagnostic criteria}

The normal values of serum TC, TG, HDL-C, LDL-C, ApoA1 and ApoB levels, and the ratio of ApoA1 to ApoB in our Clinical Science Experiment Center were 3.10-5.17, 0.56-1.70, 1.16-1.42, 2.70-3.10 mmol/L, 1.20-1.60, 0.80-1.05 $\mathrm{g} / \mathrm{L}$, and 1.00-2.50; respectively. The individuals with $\mathrm{TC}>$ $5.17 \mathrm{mmol} / \mathrm{L}$ and/or TG $>1.70 \mathrm{mmol} / \mathrm{L}$ were defined as hyperlipidemic [29,30]. Hypertension was diagnosed according to the criteria of 1999 World Health Organization-International Society of Hypertension Guidelines for the management of hypertension [33,34]. The diagnostic criteria of overweight and obesity were according to the Cooperative Meta-analysis Group of China Obesity Task Force. Normal weight, overweight and obesity were defined as a $\mathrm{BMI}<24,24-28$, and $>28 \mathrm{~kg} / \mathrm{m}^{2}$; respectively [29-34].

\section{Statistical analyses}

Epidemiological data were recorded on a pre-designed form and managed with Excel software. Data analysis was performed using the software SPSS version 19.0 (SPSS Inc., Chicago, Illinois). Quantitative variables were expressed as mean \pm standard deviation (serum TG levels were presented as medians and interquartile ranges). Qualitative variables were expressed as percentages. Allele frequency was determined via direct counting, and the standard goodness-of-fit test was used to test the HardyWeinberg equilibrium. Difference in genotype distribution between the groups was obtained using the chi-square test. The difference in general characteristics between Mulao and Han was tested by the Student's unpaired $t$-test. The association of genotypes and serum lipid parameters was tested by analysis of covariance (ANCOVA). Sex, age, BMI, blood pressure, alcohol consumption, cigarette smoking were adjusted for the statistical analysis. Multivariate linear regression analysis with stepwise modeling was performed to evaluate the association of serum lipid levels with genotypes ( $\mathrm{AA}=1, \mathrm{AG}=2$ and $\mathrm{GG}=3$ ) and several environment factors in the combined population of Mulao and Han, Mulao, Han, males and females; respectively. A $P$ value of less than 0.05 was considered statistically significant.

\section{Results}

\section{General characteristics and serum lipid levels}

The comparison of general characteristics and serum lipid levels between the Mulao and Han populations is summarized in Table 1. The levels of body weight, BMI, diastolic blood pressure were significantly lower in Mulao than in Han $(P<0.05-0.001)$, whereas the level of ApoB was higher in Mulao than in $\operatorname{Han}(P<0.001)$. There were no significant differences in the levels of systolic blood 
Table 1 Comparison of demography, lifestyle and serum lipid levels between the Mulao and Han populations

\begin{tabular}{|c|c|c|c|c|}
\hline Characteristics & Mulao & Han & $t\left(\chi^{2}\right)$ & $P$ \\
\hline Number & 639 & 644 & - & - \\
\hline Male/female & $301 / 338$ & 299/345 & -0.183 & 0.855 \\
\hline Age (years) & $53.11 \pm 14.97$ & $53.32 \pm 15.14$ & -0.314 & 0.754 \\
\hline Height (cm) & $155.38 \pm 8.23$ & $154.70 \pm 8.11$ & 1.507 & 0.132 \\
\hline Weight (kg) & 52.88. \pm 9.56 & $54.10 \pm 9.16$ & -2.369 & 0.018 \\
\hline Body mass index $\left(\mathrm{kg} / \mathrm{m}^{2}\right)$ & $21.84 \pm 3.16$ & $22.61 \pm 3.58$ & -4.102 & 0.000 \\
\hline Systolic blood pressure $(\mathrm{mmHg})$ & $130.18 \pm 22.00$ & $130.25 \pm 18.68$ & -0.089 & 0.929 \\
\hline Diastolic blood pressure (mmHg) & $81.14 \pm 11.28$ & $82.81 \pm 11.10$ & -2.664 & 0.008 \\
\hline Pulse pressure $(\mathrm{mmHg})$ & $49.04 \pm 16.65$ & $47.44 \pm 13.95$ & 1.822 & 0.069 \\
\hline Blood glucose level (mmol/L) & $6.04 \pm 1.58$ & $6.09 \pm 1.68$ & -0.498 & 0.619 \\
\hline \multicolumn{5}{|l|}{ Cigarette smoking [n (\%)] } \\
\hline Nonsmoker & $464(72.6)$ & $455(70.7)$ & & \\
\hline$<20$ cigarettes/day & $133(20.8)$ & $137(21.3)$ & & \\
\hline$\geq 20$ cigarettes/day & $42(6.5)$ & $52(8.1)$ & -0.027 & 0.978 \\
\hline \multicolumn{5}{|l|}{ Alcohol consumption [n (\%)] } \\
\hline Nondrinker & $478(74.8)$ & $485(75.3)$ & & \\
\hline$<25 \mathrm{~g} /$ day & $54(8.5)$ & $68(10.6)$ & & \\
\hline$\geq 25 \mathrm{~g} /$ day & $107(16.7)$ & $91(14.1)$ & 1.823 & 0.069 \\
\hline Total cholesterol (mmol/L) & $5.06 \pm 1.36$ & $5.07 \pm 1.12$ & -0.015 & 0.988 \\
\hline Triglyceride $(\mathrm{mmol} / \mathrm{L})$ & $1.07(0.78)$ & $1.09(0.96)$ & -0.926 & 0.354 \\
\hline $\mathrm{HDL}-\mathrm{C}(\mathrm{mmol} / \mathrm{L})$ & $1.76 \pm 0.46$ & $1.72 \pm 0.55$ & -1.114 & 0.265 \\
\hline LDL-C (mmol/L) & $2.94 \pm 0.91$ & $2.93 \pm 0.89$ & 0.290 & 0.772 \\
\hline Apolipoprotein (Apo) A1 (g/L) & $1.33 \pm 0.41$ & $1.34 \pm 0.27$ & -0.360 & 0.719 \\
\hline ApoB (g/L) & $0.97 \pm 0.52$ & $0.87 \pm 0.21$ & 4.378 & 0.000 \\
\hline Apo A1/ApoB & $1.59 \pm 0.71$ & $1.62 \pm 0.50$ & -0.983 & 0.326 \\
\hline
\end{tabular}

TC, total cholesterol; TG, triglyceride; HDL-C, high-density lipoprotein cholesterol; LDL-C, low-density lipoprotein cholesterol; ApoA1, apolipoprotein A1; ApoB, apolipoprotein B.

The values of triglyceride were presented as median (interquartile range). The difference between the two ethnic groups was determined by the Wilcoxon-MannWhitney test.

pressure, serum TC, TG, HDL-C, LDL-C, ApoA1, the ratio of ApoA1 to $A p o B$, age structure, gender ratio, height, the percentage of smoking or the percentage of alcohol consumption between the two ethnic groups $(P>$ 0.05 for all).

\section{Results of electrophoresis and genotyping}

After the genomic DNA of the samples was amplified by PCR and imaged by $2 \%$ agarose gel electrophoresis, the products of $572 \mathrm{bp}$ nucleotide sequences were found in all samples (Figure 1). The genotypes identified were named according to the presence or absence of the enzyme restriction sites, whether A or G nucleotide at rs17321515 locus of the TRIB1 gene. The presence of the cutting site indicated the A allele, while its absence indicated the $G$ allele (cannot be cut). Thus, the GG genotype was homozygote for the absence of the site (band at $572 \mathrm{bp}$ ), AG genotype was heterozygote for the presence and absence of the site (bands at 572-, 416- and 156-bp), and AA genotype was homozygote for the presence of the site (bands at 416- and 156-bp; Figure 2).

\section{Genotypic and allelic frequencies}

The genotypic and allelic frequencies of rs17321515 SNP in the TRIB1 gene are shown in Table 2. The frequencies of $\mathrm{A}$ and $\mathrm{G}$ alleles were $51.5 \%$ and $48.5 \%$ in Mulao; and $50.0 \%$ each in Han $(P>0.05)$. The frequencies of AA, AG and GG genotypes were $24.3 \%, 54.5 \%$ and $21.3 \%$ in Mulao, and $28.7 \%, 48.5 \%$ and $22.8 \%$ in $\operatorname{Han}(P>0.05)$; respectively. A significant difference in the genotypic frequencies was detected between Han males and females $(P<0.05)$ although the allelic frequencies were insignificantly different $(P>0.05)$. But there was no significant difference in the genotypic and allelic frequencies between Mulao males and females ( $P>0.05$ for each).

\section{Results of sequencing}

The results were shown as AA, AG and GG genotypes by PCR-RFLP, the AA, AG and GG genotypes were also confirmed by sequencing (Figure 3); respectively.

\section{Genotypes and serum lipid levels}

As shown in Table 3, the levels of HDL-C and LDL-C in Han but not in Mulao were different among the AA, 


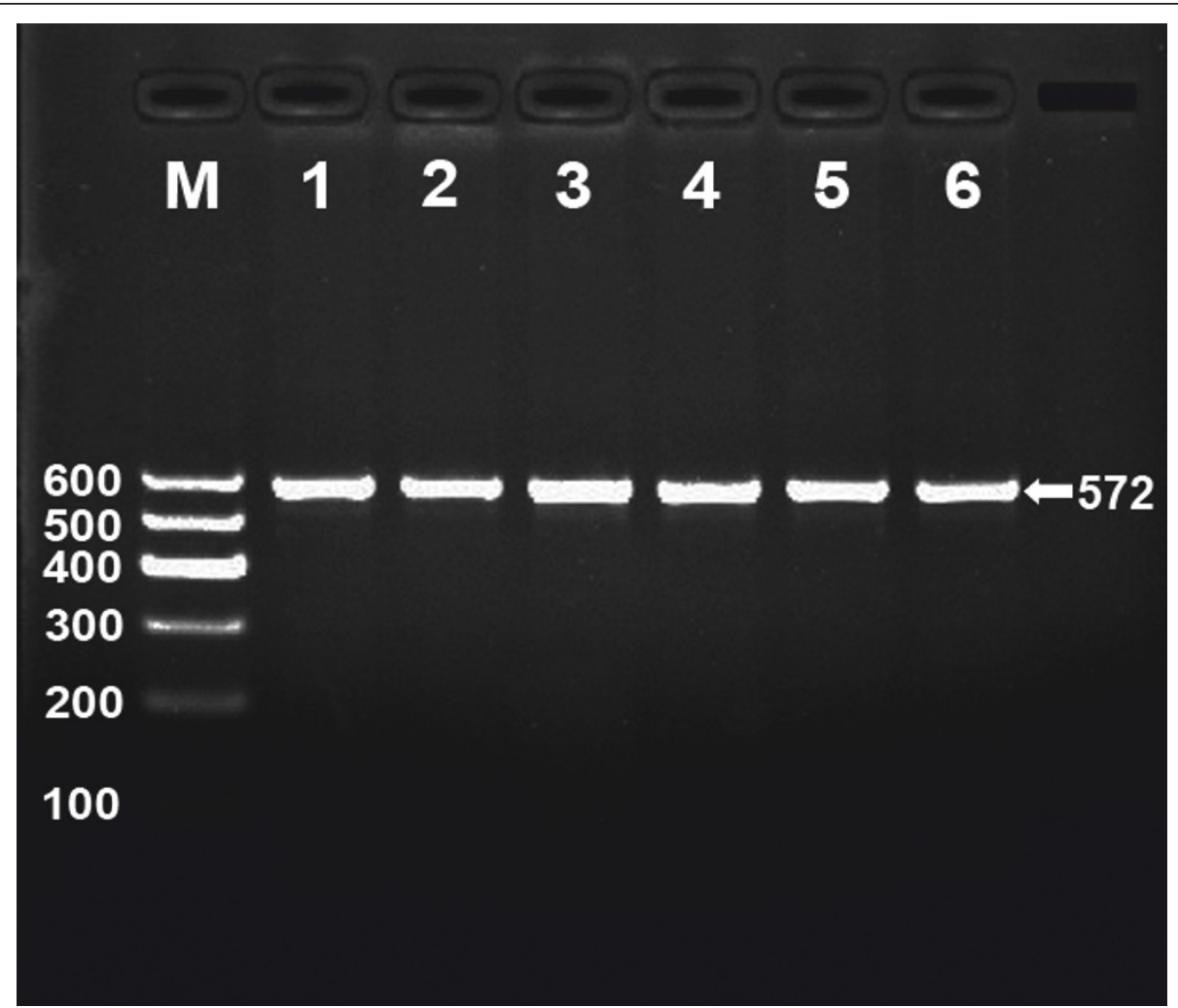

Figure 1 Electrophoresis of PCR products of the samples. Lane M, 100 bp marker ladder; lanes 1-6, samples. The 572 bp bands are the target genes.

AG and GG genotypes $(P<0.05$ for each), the subjects with AG/GG genotypes had higher serum HDL-C and LDL-C levels than the subjects with AA genotype. Subgroup analyses showed that the levels of TC, HDL-C, LDL-C, ApoA1 and ApoB in Han males but not in females were different among the three genotypes $(P<$ 0.05-0.001), the G carriers had higher serum TC, HDLC, LDL-C, ApoA1 and ApoB levels than the G noncarriers. Besides, the levels of HDL-C in Mulao males were different among the three genotypes $(P<0.05)$, the $\mathrm{G}$ carriers had lower serum HDL-C levels than the $G$ noncarriers.

\section{Relative factors for serum lipid parameters}

The multiple linear regression analysis showed that the levels of serum HDL-C and LDL-C were correlated with the genotypes or alleles in both ethnic groups. The levels of TG in Han was also correlated with the genotypes $(P<0.05-0.01$; Table 4$)$.

As shown in Table 5, when the lipid data were analyzed according to gender, the levels of TG and HDL-C in Mulao were correlated with genotypes in males but not in females $(P<0.05$ for each). The levels of TG, HDL-C, LDL-C and ApoA1 in Han were associated with genotypes or alleles in males, and the levels of TG and ApoA1 were associated with genotypes in females $(P<0.05-0.001)$.

Serum lipid parameters were also associated with age, gender, BMI, systolic and diastolic blood pressure, fasting blood glucose levels and alcohol consumption in both ethnic groups $(P<0.05-0.001$, Tables 4 and 5).

\section{Discussion}

By comparison of serum lipid levels between the participants of Mulao and Han nationalities, we showed that the levels of ApoB were higher in Mulao than in Han $(P$ $<0.05)$. There were no significant differences in the levels of TC, HDL-C, LDL-C, ApoA1, and the ratio of ApoA1 to ApoB between the two ethnic groups. These findings are not fully consistent with those of our recent study [27]. In the previous study, we showed that both LDL-C and ApoB levels were higher in Mulao than in Han [27]. This discrepancy may be related to the different sampling from our previous stratified randomized cluster samples. It is well recognized that serum lipid levels are influenced by both environmental factors including demographics, diet, alcohol consumption, cigarette smoking, obesity, exercise, hypertension $[8,9]$ and genetic factors such as variants in genes coding for proteins functioning lipid metabolism; and their 


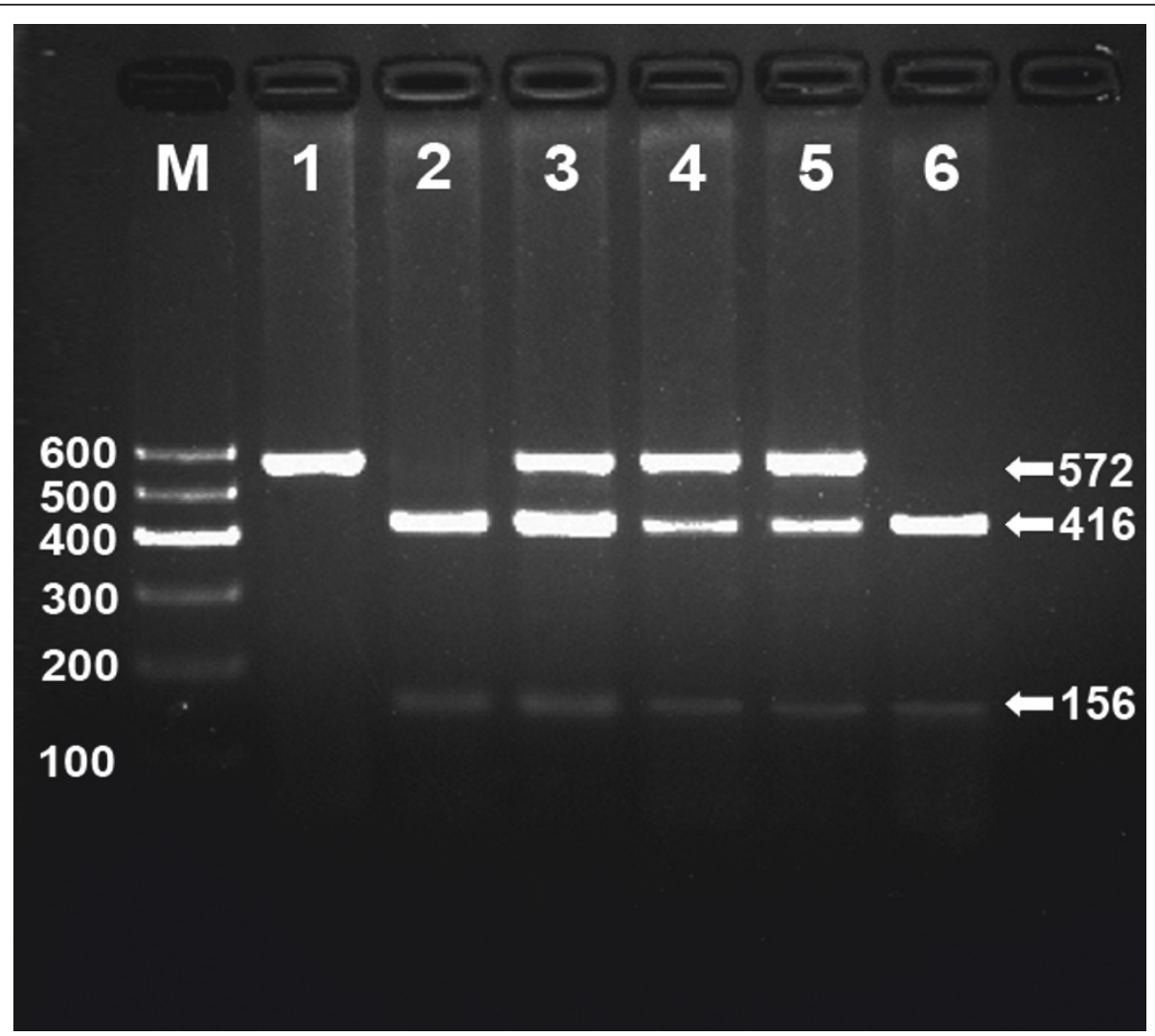

Figure 2 Genotyping of the TRIB1 rs17321515 SNP. Lane M, 100 bp marker ladder; lane 1, GG genotype (572 bp); lanes 2 and 6, AA genotype (416- and 156-bp); and lanes 3, 4 and 5, AG genotype (572-, 416- and 156-bp).

interactions $[10,11]$ as well as ethnic diversities. Mulao people have been abided with their special customs especially in case of marriage. Their marriages were family-arranged since childhood. However, divorce and remarriage were also allowed. Although the marriage was arranged at childhood, it was celebrated only when the girl reached puberty. Traditionally, until before a Mulao girl delivered her first child, she stayed with her parents and was unrestricted to join the young people social activities such as responsive singing, flirtations,

Table 2 Comparison of the genotypic and allelic frequencies between the Mulao and Han populations [n (\%)]

\begin{tabular}{|c|c|c|c|c|c|c|}
\hline \multirow[t]{2}{*}{ Group } & \multirow[t]{2}{*}{$n$} & \multicolumn{3}{|c|}{ Genotype } & \multicolumn{2}{|c|}{ Allele } \\
\hline & & $\mathrm{AA}$ & AG & GG & A & G \\
\hline Mulao & 639 & $155(24.3)$ & $348(54.5)$ & $136(21.2)$ & $658(51.5)$ & $620(48.5)$ \\
\hline Han & 644 & 185(28.7) & $312(48.5)$ & $147(22.8)$ & $682(50.0)$ & $682(50.0)$ \\
\hline$\chi^{2}$ & - & & 5.019 & & & \\
\hline P & - & & 0.081 & & & \\
\hline \multicolumn{7}{|l|}{ Mulao } \\
\hline Male & 301 & $80(26.6)$ & 155(51.5) & $66(21.9)$ & $315(52.3)$ & $287(47.7)$ \\
\hline Female & 338 & $75(22.2)$ & 193(57.1) & $70(20.7)$ & $343(50.7)$ & $333(49.3)$ \\
\hline$\chi^{2}$ & - & & 2.662 & & & \\
\hline P & - & & 0.264 & & & \\
\hline \multicolumn{7}{|l|}{ Han } \\
\hline Male & 299 & $73(24.4)$ & $160(53.5)$ & $66(22.1)$ & $306(51.2)$ & $292(48.8)$ \\
\hline Female & 345 & $112(32.5)$ & 152(44.0) & $81(23.5)$ & $376(54.5)$ & $314(45.5)$ \\
\hline$\chi^{2}$ & - & & 6.706 & & & \\
\hline P & - & & 0.035 & & & \\
\hline
\end{tabular}




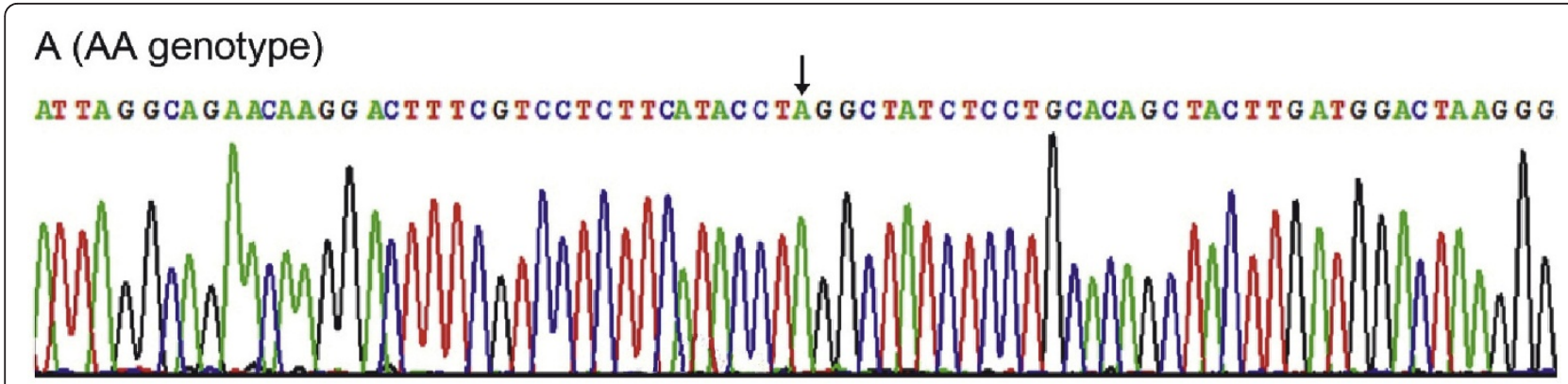

\section{B (AG genotype)}

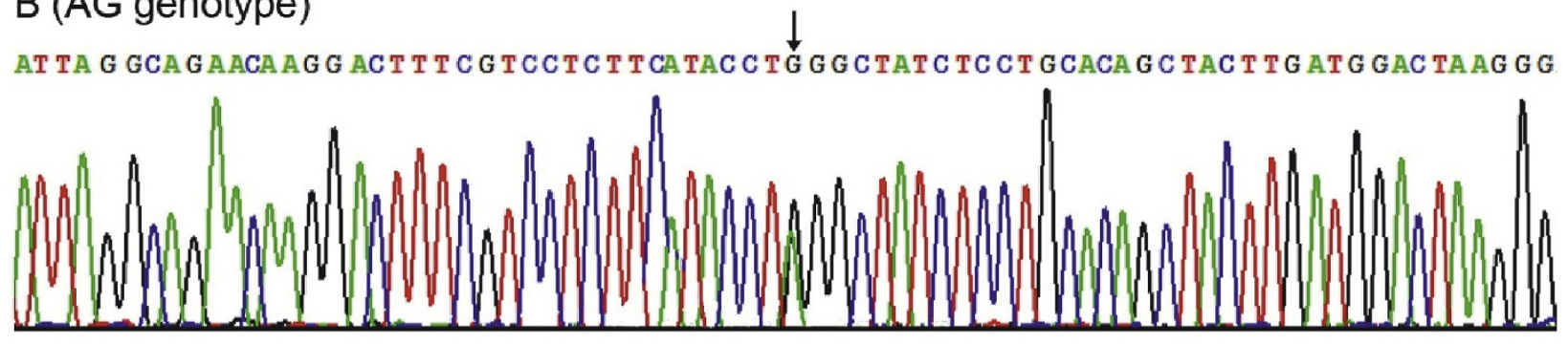

\section{C (GG genotype)}
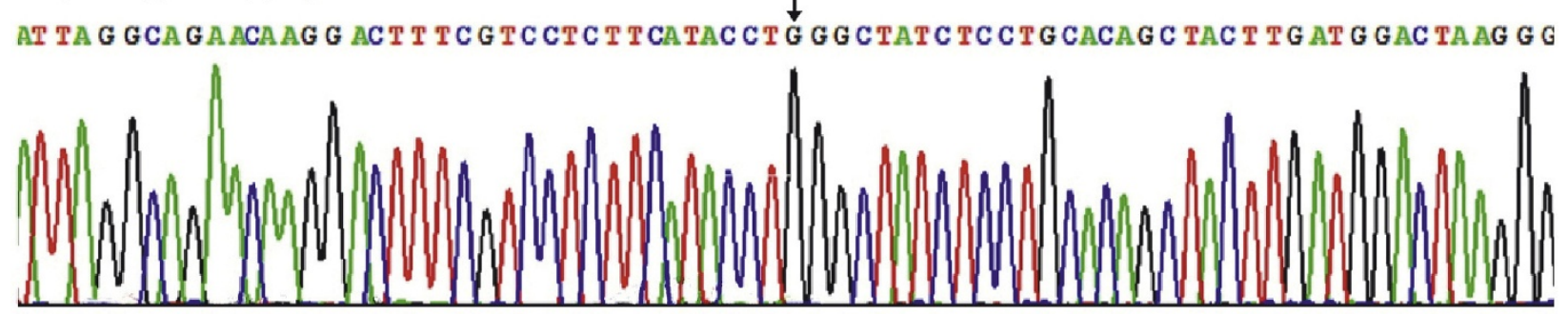

Figure 3 A part of the nucleotide sequence of the TRIB1 rs17321515 SNP. (A) AA genotype; (B) AG genotype; (C) GG genotype.

and courtships at festival times. The age of the wife was usually four or five years older than that of the husband. Engagement and marriage were socially accepted with bride-wealth payment. Interestingly, there was a preference of marriage to cousins from maternal side (mother's brother's daughter). Therefore, it is compelling us to believe that some hereditary characteristics and genotypes of lipid metabolism-related genes in this population may be different from those in Han nationality [35-38].

The genotypic and allelic frequencies of TRIB1 rs17321515 SNP in different studies were slightly dissimilar. In a genome-wide association study of nearly 10000 participants of European ancestry and Asians, the frequencies of A and G alleles were $55.0 \%$ and $45.0 \%$ [15], which is similar to those of British population [17]. Another study detecting the polygenic determinants of severe hypertriglyceridemia found that the frequencies of AA, AG and GG genotypes were $42.4 \%, 47.0 \%$ and $10.6 \%$ in hypertriglyceridemic patients and $28.2 \%, 47.6 \%$ and $24.2 \%$ in normal controls [25]. In a Spanish familial hypercholesterolemia cohort study, the frequencies of AA, AG and GG genotypes were $30.3 \%, 51.0 \%$ and $19.6 \%$; respectively [39]. Hegele et al. [40] reported that the percentages of $A$ and $G$ alleles were $51-68 \%$ and $32-49 \%$ in classical Fredrickson hyperlipoproteinemic patients. The frequencies of $\mathrm{A}$ and $\mathrm{G}$ alleles were $48.0 \%$ and $52.0 \%$ in Japanese population [41], which was similar to those in Malay population [24]. The minor allele frequency was $44.0 \%$ in Korean population which is similar to that of European ancestry. In our present study, the frequency of G allele was $48.5 \%$ in Mulao and $50.0 \%$ in Han, which were closer to that of Japanese and Asian Malay populations. There was no significant difference in both genotypic and allelic frequencies between the Mulao and Han populations. We felt that biologically, Mulao and Han nationalities might be homologous. Upon considering the gender, the genotypic frequency in Han but not in Mulao 
Table 3 Comparison of serum lipid levels among the genotypes between the Mulao and Han populations

\begin{tabular}{|c|c|c|c|c|c|c|c|c|}
\hline Genotype & $n$ & $\begin{array}{c}\mathrm{TC} \\
(\mathrm{mmol} / \mathrm{L})\end{array}$ & $\begin{array}{c}\text { TG } \\
(\mathrm{mmol} / \mathrm{L})\end{array}$ & $\begin{array}{c}\mathrm{HDL}-\mathrm{C} \\
(\mathrm{mmol} / \mathrm{L})\end{array}$ & $\begin{array}{c}\mathrm{LDL}-\mathrm{C} \\
(\mathrm{mmol} / \mathrm{L})\end{array}$ & $\begin{array}{l}\text { ApoA1 } \\
\text { (g/L) }\end{array}$ & $\begin{array}{c}\text { ApoB } \\
\text { (g/L) }\end{array}$ & $\begin{array}{c}\text { ApoA1/ } \\
\text { ApoB }\end{array}$ \\
\hline \multicolumn{9}{|l|}{ Mulao } \\
\hline $\mathrm{AA}$ & 155 & $5.13 \pm 1.07$ & $1.10(0.75)$ & $1.80 \pm 0.54$ & $3.05 \pm 0.88$ & $1.34 \pm 0.43$ & $1.00 \pm 0.61$ & $1.61 \pm 0.85$ \\
\hline$A G$ & 348 & $5.05 \pm 1.28$ & 1.04(0.79) & $1.75 \pm 0.44$ & $2.93 \pm 0.91$ & $1.35 \pm 0.39$ & $0.96 \pm 0.49$ & $1.60 \pm 0.63$ \\
\hline GG & 136 & $5.02 \pm 1.82$ & $1.09(0.90)$ & $1.71 \pm 0.41$ & $2.84 \pm 0.93$ & $1.27 \pm 0.43$ & $0.94 \pm 0.49$ & $1.54 \pm 0.71$ \\
\hline$F$ & - & 0.283 & 1.492 & 2.316 & 1.882 & 2.073 & 0.450 & 0.396 \\
\hline P & - & 0.754 & 0.474 & 0.099 & 0.153 & 0.127 & 0.638 & 0.673 \\
\hline $\mathrm{AA}$ & 155 & $5.13 \pm 1.07$ & $1.10(0.75)$ & $1.82 \pm 0.54$ & $3.05 \pm 0.88$ & $1.34 \pm 0.43$ & $1.00 \pm 0.61$ & $1.61 \pm 0.85$ \\
\hline$A G / G G$ & 484 & $5.05 \pm 1.44$ & $1.05(0.80)$ & $1.74 \pm 0.43$ & $2.91 \pm 0.92$ & $1.33 \pm 0.40$ & $0.96 \pm 0.49$ & $1.58 \pm 0.65$ \\
\hline$F$ & - & 0.410 & -0.904 & 3.700 & 2.754 & 0.052 & 0.754 & 0.208 \\
\hline P & - & 0.522 & 0.366 & 0.055 & 0.097 & 0.819 & 0.385 & 0.648 \\
\hline \multicolumn{9}{|l|}{ Male } \\
\hline AA & 80 & $5.13 \pm 0.86$ & $1.09(1.20)$ & $1.84 \pm 0.63$ & $2.99 \pm 0.69$ & $1.37 \pm 0.44$ & $1.04 \pm 0.67$ & $1.59 \pm 0.80$ \\
\hline$A G$ & 155 & $5.22 \pm 1.30$ & $1.19(1.11)$ & $1.76 \pm 0.45$ & $2.91 \pm 0.87$ & $1.39 \pm 0.39$ & $0.98 \pm 0.49$ & $1.58 \pm 0.59$ \\
\hline GG & 66 & $5.11 \pm 2.30$ & $1.29(1.12)$ & $1.63 \pm 0.40^{\mathrm{a}}$ & $2.75 \pm 0.97$ & $1.28 \pm 0.48$ & $1.03 \pm 0.61$ & $1.45 \pm 0.68$ \\
\hline$F$ & - & 0.154 & 3.403 & 3.652 & 1.510 & 1.577 & 0.358 & 1.017 \\
\hline$P$ & - & 0.858 & 0.182 & 0.027 & 0.223 & 0.208 & 0.700 & 0.363 \\
\hline \multicolumn{9}{|l|}{ Female } \\
\hline AA & 75 & $5.14 \pm 1.26$ & $1.19(0.72)$ & $1.79 \pm 0.42$ & $3.09 \pm 1.05$ & $1.30 \pm 0.41$ & $0.96 \pm 0.51$ & $1.62 \pm 0.90$ \\
\hline$A G$ & 193 & $4.92 \pm 1.25$ & $1.00(0.64)$ & $1.74 \pm 0.44$ & $2.96 \pm 0.95$ & $1.32 \pm 0.38$ & $0.94 \pm 0.50$ & $1.62 \pm 0.66$ \\
\hline GG & 70 & $4.93 \pm 1.17$ & $1.03(0.60)$ & $1.77 \pm 0.41$ & $2.91 \pm 0.88$ & $1.25 \pm 0.39$ & $0.86 \pm 0.35$ & $1.63 \pm 0.73$ \\
\hline$F$ & - & 0.954 & 2.297 & 0.325 & 0.686 & 0.714 & 1.006 & 0.005 \\
\hline P & - & 0.386 & 0.317 & 0.723 & 0.505 & 0.491 & 0.367 & 0.995 \\
\hline \multicolumn{9}{|l|}{ Han } \\
\hline $\mathrm{AA}$ & 185 & $4.97 \pm 1.18$ & $1.23(1.07)$ & $1.63 \pm 0.41$ & $2.79 \pm 0.85$ & $1.32 \pm 0.25$ & $0.86 \pm 0.18$ & $1.62 \pm 0.54$ \\
\hline$A G$ & 312 & $5.11 \pm 1.10$ & $1.08(1.01)$ & $1.78 \pm 0.65^{\mathrm{a}}$ & $3.00 \pm 0.87^{\mathrm{a}}$ & $1.35 \pm 0.25$ & $0.87 \pm 0.21$ & $1.63 \pm 0.46$ \\
\hline GG & 147 & $5.10 \pm 1.11$ & $1.00(0.70)$ & $1.73 \pm 0.48$ & $2.95 \pm 0.96$ & $1.33 \pm 0.31$ & $0.88 \pm 0.24$ & $1.61 \pm 0.55$ \\
\hline$F$ & - & 0.926 & 6.130 & 4.275 & 3.359 & 0.975 & 0.458 & 0.112 \\
\hline P & - & 0.397 & 0.047 & 0.014 & 0.035 & 0.378 & 0.633 & 0.894 \\
\hline $\mathrm{AA}$ & 185 & $4.99 \pm 1.18$ & $1.23(1.06)$ & $1.64 \pm 0.41$ & $2.79 \pm 0.85$ & $1.33 \pm 0.25$ & $0.86 \pm 0.18$ & $1.62 \pm 0.54$ \\
\hline $\mathrm{AG} / \mathrm{GG}$ & 459 & $5.10 \pm 1.10$ & $1.05(0.95)$ & $1.76 \pm 0.60$ & $2.98 \pm 0.90$ & $1.34 \pm 0.27$ & $0.87 \pm 0.22$ & $1.62 \pm 0.49$ \\
\hline$F$ & - & 1.403 & -1.756 & 6.598 & 6.749 & 0.609 & 0.507 & 0.002 \\
\hline P & - & 0.237 & 0.079 & 0.010 & 0.010 & 0.435 & 0.477 & 0.963 \\
\hline \multicolumn{9}{|l|}{ Male } \\
\hline AA & 73 & $4.98 \pm 1.29$ & $1.30(0.93)$ & $1.53 \pm 0.38$ & $2.62 \pm 0.75$ & $1.27 \pm 0.26$ & $0.88 \pm 0.19$ & $1.49 \pm 0.47$ \\
\hline$A G$ & 160 & $5.35 \pm 1.12^{\mathrm{a}}$ & $1.30(1.10)$ & $1.69 \pm 0.40^{\mathrm{a}}$ & $3.14 \pm 0.83^{\mathrm{a}}$ & $1.37 \pm 0.27^{\mathrm{a}}$ & $0.94 \pm 0.21$ & $1.53 \pm 0.42$ \\
\hline GG & 66 & $5.41 \pm 1.05^{a}$ & $1.15(1.16)$ & $1.74 \pm 0.47^{\mathrm{a}}$ & $3.14 \pm 0.90^{\mathrm{a}}$ & $1.41 \pm 0.33^{\mathrm{a}}$ & $0.97 \pm 0.24^{\mathrm{a}}$ & $1.52 \pm 0.49$ \\
\hline$F$ & - & 3.178 & 0.329 & 5.594 & 10.859 & 5.919 & 3.302 & 0.234 \\
\hline P & - & 0.043 & 0.848 & 0.004 & 0.000 & 0.003 & 0.038 & 0.791 \\
\hline \multicolumn{9}{|l|}{ Female } \\
\hline$A A$ & 112 & $4.94 \pm 1.10$ & $1.15(1.09)$ & $1.72 \pm 0.41$ & $2.89 \pm 0.90$ & $1.35 \pm 0.25$ & $0.83 \pm 0.17$ & $1.72 \pm 0.56$ \\
\hline$A G$ & 152 & $4.87 \pm 1.04$ & $0.97(0.81)$ & $1.85 \pm 0.83$ & $2.84 \pm 0.89$ & $1.33 \pm 0.24$ & $0.82 \pm 0.20$ & $1.72 \pm 0.47$ \\
\hline GG & 81 & $4.86 \pm 1.09$ & $0.95(0.60)$ & $1.72 \pm 0.49$ & $2.82 \pm 0.98$ & $1.28 \pm 0.29$ & $0.80 \pm 0.21$ & $1.68 \pm 0.59$ \\
\hline$F$ & - & 0.199 & 4.704 & 2.020 & 0.190 & 1.903 & 0.461 & 0.171 \\
\hline P & - & 0.820 & 0.095 & 0.134 & 0.827 & 0.151 & 0.631 & 0.843 \\
\hline
\end{tabular}

TC, total cholesterol; TG, triglyceride; HDL-C, high-density lipoprotein cholesterol; LDL-C, low-density lipoprotein cholesterol; ApoA1, apolipoprotein A1; ApoB, apolipoprotein $B$. The values of triglyceride were presented as median (interquartile range). The difference among the genotypes was determined by the KruskalWallis test or the Wilcoxon-Mann-Whitney test. ${ }^{\mathrm{a}} P<0.05$ comparison with AA genotype of the same ethnic group.

was different between males and female $(P<0.05)$. These results indicate that the genotype distribution of TRIB1 rs17321515 SNP may have a sex specificity.
Many genome-wide studies have reported that the TRIB1 rs17321515 SNP was associated with variation in serum levels of LDL-C, HDL-C and TG. Kathiresan et al. 
Table 4 Relative risk factors for serum lipid parameters in the Mulao and Han populations

\begin{tabular}{|c|c|c|c|c|c|c|}
\hline $\begin{array}{l}\text { Lipid } \\
\text { parameter }\end{array}$ & Risk factor & $\begin{array}{c}\text { Unstandardized } \\
\text { coefficient }\end{array}$ & Standard error & $\begin{array}{c}\text { Standardized } \\
\text { coefficient }\end{array}$ & $t$ & $P$ \\
\hline \multicolumn{7}{|l|}{ Mulao/Han } \\
\hline \multirow[t]{3}{*}{$\mathrm{TC}$} & Alcohol comsumption & 0.232 & 0.047 & 0.137 & 4.892 & 0.000 \\
\hline & Body mass index & 0.045 & 0.010 & 0.121 & 4.324 & 0.000 \\
\hline & Age & 0.097 & 0.025 & 0.107 & 3.875 & 0.000 \\
\hline \multirow[t]{4}{*}{$\mathrm{TG}$} & Gender & -0.517 & 0.162 & -0.105 & -3.199 & 0.001 \\
\hline & Alcohol comsumption & 0.491 & 0.093 & 0.148 & 5.287 & 0.000 \\
\hline & Body mass index & 0.095 & 0.020 & 0.132 & 4.720 & 0.000 \\
\hline & Blood glucose level & 0.145 & 0.042 & 0.096 & 3.475 & 0.001 \\
\hline \multirow[t]{3}{*}{$\mathrm{HDL}-\mathrm{C}$} & Body mass index & -0.030 & 0.004 & -0.200 & -7.136 & 0.000 \\
\hline & Alcohol comsumption & 0.079 & 0.019 & 0.115 & 4.103 & 0.000 \\
\hline & Gender & 0.144 & 0.034 & 0.140 & 4.298 & 0.000 \\
\hline \multirow[t]{2}{*}{ LDL-C } & Body mass index & 0.042 & 0.007 & 0.159 & 5.720 & 0.000 \\
\hline & Age & 0.083 & 0.018 & 0.127 & 4.589 & 0.000 \\
\hline \multirow[t]{3}{*}{ ApoA1 } & Alcohol comsumption & 0.116 & 0.013 & 0.249 & 8.995 & 0.000 \\
\hline & Body mass index & -0.009 & 0.003 & -0.088 & -3.171 & 0.002 \\
\hline & Gender & 0.053 & 0.023 & 0.077 & 2.355 & 0.019 \\
\hline \multirow[t]{4}{*}{ ApoB } & Body mass index & 0.021 & 0.003 & 0.175 & 6.325 & 0.000 \\
\hline & Ethnic group & -0.112 & 0.022 & -0.139 & -5.070 & 0.000 \\
\hline & Blood glucose level & 0.026 & 0.007 & 0.104 & 3.800 & 0.000 \\
\hline & Gender & -0.084 & 0.022 & -0.104 & -3.778 & 0.000 \\
\hline \multirow[t]{5}{*}{ ApoA1/ApoB } & Body mass index & -0.042 & 0.005 & -0.240 & -8.851 & 0.000 \\
\hline & Blood glucose level & -0.045 & 0.010 & -0.123 & -4.446 & 0.000 \\
\hline & Alcohol comsumption & 0.132 & 0.026 & 0.162 & 5.051 & 0.000 \\
\hline & Gender & 0.193 & 0.038 & 0.160 & 5.011 & 0.000 \\
\hline & Age & -0.030 & 0.012 & -0.069 & -2.510 & 0.012 \\
\hline \multicolumn{7}{|l|}{ Mulao } \\
\hline \multirow[t]{3}{*}{$\mathrm{TC}$} & Body mass index & 0.062 & 0.017 & 0.143 & 3.665 & 0.000 \\
\hline & Alcohol consumption & 0.196 & 0.070 & 0.110 & 2.800 & 0.005 \\
\hline & Age & 0.081 & 0.038 & 0.083 & 2.135 & 0.033 \\
\hline \multirow[t]{2}{*}{ TG } & Alcohol consumption & 0.548 & 0.110 & 0.193 & 4.991 & 0.000 \\
\hline & Body mass index & 0.107 & 0.026 & 0.156 & 4.032 & 0.000 \\
\hline \multirow[t]{4}{*}{$\mathrm{HDL}-\mathrm{C}$} & Body mass index & -0.038 & 0.006 & -0.258 & -6.793 & 0.000 \\
\hline & Alcohol consumption & 0.126 & 0.028 & 0.207 & 4.536 & 0.000 \\
\hline & Gender & 0.099 & 0.042 & 0.107 & 2.339 & 0.020 \\
\hline & Genotype & -0.052 & 0.026 & -0.075 & -1.970 & 0.049 \\
\hline \multirow[t]{4}{*}{ LDL-C } & Body mass index & 0.054 & 0.011 & 0.188 & 4.830 & 0.000 \\
\hline & Alcohol consumption & -0.117 & 0.047 & -0.098 & -2.525 & 0.012 \\
\hline & Age & 0.059 & 0.025 & 0.091 & 2.353 & 0.019 \\
\hline & Genotype & -0.105 & 0.053 & -0.077 & -1.979 & 0.048 \\
\hline \multirow[t]{2}{*}{ ApoA1 } & Alcohol consumption & 0.120 & 0.021 & 0.225 & 5.822 & 0.000 \\
\hline & Blood glucose level & -0.020 & 0.010 & -0.077 & -1.996 & 0.046 \\
\hline ApoB & Body mass index & 0.028 & 0.006 & 0.167 & 4.264 & 0.000 \\
\hline \multirow[t]{4}{*}{ ApoA1/ApoB } & Body mass index & -0.044 & 0.009 & -0.198 & -5.154 & 0.000 \\
\hline & Blood glucose level & -0.052 & 0.017 & -0.117 & -3.046 & 0.002 \\
\hline & Alcohol consumption & 0.158 & 0.043 & 0.172 & 3.723 & 0.000 \\
\hline & Gender & 0.170 & 0.065 & 0.121 & 2.622 & 0.009 \\
\hline \multicolumn{7}{|l|}{ Han } \\
\hline \multirow[t]{4}{*}{$\mathrm{TC}$} & Alcohol consumption & 0.175 & 0.071 & 0.111 & 2.449 & 0.015 \\
\hline & Diastolic blood pressure & 0.020 & 0.004 & 0.193 & 4.949 & 0.000 \\
\hline & Gender & -0.237 & 0.103 & -0.105 & -2.309 & 0.021 \\
\hline & Blood glucose level & 0.080 & 0.026 & 0.119 & 3.070 & 0.002 \\
\hline
\end{tabular}


Table 4 Relative risk factors for serum lipid parameters in the Mulao and Han populations (Continued)

\begin{tabular}{|c|c|c|c|c|c|c|}
\hline \multirow[t]{5}{*}{$\mathrm{TG}$} & Gender & -0.948 & 0.215 & -0.173 & -4.405 & 0.000 \\
\hline & Blood glucose level & 0.245 & 0.065 & 0.151 & 3.759 & 0.000 \\
\hline & Diastolic blood pressure & 0.038 & 0.010 & 0.155 & 3.800 & 0.000 \\
\hline & Age & -0.241 & 0.083 & -0.122 & -2.915 & 0.004 \\
\hline & Genotype & -0.368 & 0.151 & -0.095 & -2.442 & 0.015 \\
\hline \multirow[t]{4}{*}{$\mathrm{HDL}-\mathrm{C}$} & Body mass index & -0.021 & 0.006 & -0.135 & -3.331 & 0.001 \\
\hline & Alcohol consumption & 0.133 & 0.036 & 0.172 & 3.668 & 0.000 \\
\hline & Gender & 0.207 & 0.052 & 0.185 & 3.960 & 0.000 \\
\hline & Allele & 0.120 & 0.050 & 0.096 & 2.412 & 0.016 \\
\hline \multirow[t]{4}{*}{ LDL-C } & Body mass index & 0.038 & 0.010 & 0.154 & 3.932 & 0.000 \\
\hline & Age & 0.093 & 0.026 & 0.144 & 3.560 & 0.000 \\
\hline & Allele & 0.209 & 0.078 & 0.104 & 2.666 & 0.008 \\
\hline & Blood glucose level & 0.054 & 0.021 & 0.103 & 2.544 & 0.011 \\
\hline \multirow[t]{2}{*}{ ApoA1 } & Alcohol consumption & 0.111 & 0.015 & 0.297 & 7.561 & 0.000 \\
\hline & Body mass index & -0.013 & 0.003 & -0.178 & -4.526 & 0.000 \\
\hline \multirow[t]{5}{*}{ ApoB } & Body mass index & 0.014 & 0.002 & 0.241 & 6.551 & 0.000 \\
\hline & Blood glucose level & 0.033 & 0.004 & 0.263 & 7.435 & 0.000 \\
\hline & Gender & -0.076 & 0.017 & -0.181 & -4.370 & 0.000 \\
\hline & Diastolic blood pressure & 0.003 & 0.001 & 0.140 & 3.843 & 0.000 \\
\hline & Alcohol consumption & 0.027 & 0.012 & 0.094 & 2.243 & 0.025 \\
\hline \multirow[t]{5}{*}{ ApoA1/ApoB } & Body mass index & -0.039 & 0.005 & -0.292 & -7.634 & 0.000 \\
\hline & Blood glucose level & -0.050 & 0.010 & -0.175 & -4.766 & 0.000 \\
\hline & Alcohol consumption & 0.113 & 0.029 & 0.170 & 3.889 & 0.000 \\
\hline & Gender & 0.212 & 0.041 & 0.222 & 5.141 & 0.000 \\
\hline & Diastolic blood pressure & -0.005 & 0.002 & -0.116 & -3.064 & 0.002 \\
\hline
\end{tabular}

TC, total cholesterol; TG, triglyceride; HDL-C, high-density lipoprotein cholesterol; LDL-C, low-density lipoprotein cholesterol; ApoA1, apolipoprotein A1; ApoB, apolipoprotein B.

Table 5 Correlative factors for serum lipid parameters between males and females in both ethnic groups

\begin{tabular}{|c|c|c|c|c|c|c|}
\hline $\begin{array}{c}\text { Lipid } \\
\text { parameter }\end{array}$ & Risk factor & $\begin{array}{c}\text { Unstandardized } \\
\text { coefficient }\end{array}$ & Standard error & $\begin{array}{c}\text { Standardized } \\
\text { coefficient }\end{array}$ & $t$ & $P$ \\
\hline \multicolumn{7}{|l|}{ Mulao } \\
\hline \multicolumn{7}{|l|}{ Male } \\
\hline \multirow[t]{2}{*}{$\mathrm{TC}$} & Body mass index & 0.061 & 0.027 & 0.128 & 2.225 & 0.027 \\
\hline & Alcohol consumption & 0.205 & 0.095 & 0.124 & 2.161 & 0.031 \\
\hline \multirow[t]{3}{*}{ TG } & Body mass index & 0.165 & 0.054 & 0.172 & 3.044 & 0.003 \\
\hline & Alcohol consumption & 0.468 & 0.189 & 0.140 & 2.475 & 0.014 \\
\hline & Genotype & 0.519 & 0.246 & 0.119 & 2.110 & 0.036 \\
\hline \multirow[t]{3}{*}{$\mathrm{HDL}-\mathrm{C}$} & Body mass index & -0.041 & 0.009 & -0.256 & -4.679 & 0.000 \\
\hline & Alcohol consumption & 0.135 & 0.030 & 0.244 & 4.459 & 0.000 \\
\hline & Genotype & -0.098 & 0.039 & -0.135 & -2.485 & 0.014 \\
\hline \multirow[t]{2}{*}{ ApoA1 } & Alcohol consumption & 0.143 & 0.026 & 0.305 & 5.579 & 0.000 \\
\hline & Blood glucose level & -0.032 & 0.013 & -0.135 & -2.473 & 0.014 \\
\hline ApoB & Body mass index & 0.021 & 0.011 & 0.114 & 1.984 & 0.048 \\
\hline \multirow[t]{3}{*}{ ApoA1/ApoB } & Alcohol consumption & 0.167 & 0.041 & 0.225 & 4.094 & 0.000 \\
\hline & Body mass index & -0.049 & 0.012 & -0.232 & -4.228 & 0.000 \\
\hline & Blood glucose level & -0.057 & 0.020 & -0.152 & -2.768 & 0.006 \\
\hline \multicolumn{7}{|l|}{ Female } \\
\hline \multirow[t]{2}{*}{ TC } & Body mass index & 0.061 & 0.021 & 0.157 & 2.926 & 0.004 \\
\hline & Age & 0.122 & 0.047 & 0.138 & 2.571 & 0.011 \\
\hline TG & Body mass index & 0.053 & 0.013 & 0.212 & 3.970 & 0.000 \\
\hline
\end{tabular}


Table 5 Correlative factors for serum lipid parameters between males and females in both ethnic groups (Continued)

\begin{tabular}{|c|c|c|c|c|c|c|}
\hline $\mathrm{HDL}-\mathrm{C}$ & Body mass index & -0.036 & 0.007 & -0.267 & -5.074 & 0.000 \\
\hline \multirow[t]{2}{*}{ LDL-C } & Body mass index & 0.071 & 0.016 & 0.235 & 4.470 & 0.000 \\
\hline & Age & 0.099 & 0.036 & 0.144 & 2.742 & 0.006 \\
\hline ApoA1 & Diastolic blood pressure & 0.004 & 0.002 & 0.120 & 2.213 & 0.028 \\
\hline \multirow[t]{2}{*}{ ApoB } & Body mass index & 0.031 & 0.008 & 0.210 & 3.956 & 0.000 \\
\hline & Age & 0.036 & 0.018 & 0.108 & 2.039 & 0.042 \\
\hline \multirow{2}{*}{ ApoA1/ApoB } & Body mass index & -0.042 & 0.012 & -0.182 & -3.420 & 0.001 \\
\hline & Age & -0.075 & 0.028 & -0.144 & -2.708 & 0.007 \\
\hline \multicolumn{7}{|l|}{ Han } \\
\hline \multicolumn{7}{|l|}{ Male } \\
\hline \multirow[t]{3}{*}{ TC } & Alcohol consumption & 0.180 & 0.077 & 0.132 & 2.339 & 0.020 \\
\hline & Diastolic blood pressure & 0.027 & 0.006 & 0.265 & 4.697 & 0.000 \\
\hline & Blood glucose level & 0.077 & 0.037 & 0.115 & 2.056 & 0.041 \\
\hline \multirow[t]{3}{*}{ TG } & Body mass index & 0.165 & 0.054 & 0.172 & 3.044 & 0.003 \\
\hline & Alcohol consumption & 0.468 & 0.189 & 0.140 & 2.475 & 0.014 \\
\hline & Genotype & 0.519 & 0.246 & 0.119 & 2.110 & 0.036 \\
\hline \multirow[t]{4}{*}{$\mathrm{HDL}-\mathrm{C}$} & Body mass index & -0.027 & 0.006 & -0.261 & -4.721 & 0.000 \\
\hline & Alcohol consumption & 0.129 & 0.027 & 0.263 & 4.759 & 0.000 \\
\hline & Allele & 0.176 & 0.055 & 0.174 & 3.180 & 0.002 \\
\hline & Blood glucose level & -0.028 & 0.013 & -0.117 & -2.150 & 0.032 \\
\hline \multirow[t]{3}{*}{ LDL-C } & Allele & 0.563 & 0.118 & 0.271 & 4.781 & 0.000 \\
\hline & Systolic blood pressure & 0.005 & 0.003 & 0.120 & 2.106 & 0.036 \\
\hline & Blood glucose level & 0.058 & 0.028 & 0.119 & 2.103 & 0.036 \\
\hline \multirow[t]{3}{*}{ ApoA1 } & Alcohol consumption & 0.134 & 0.018 & 0.405 & 7.529 & 0.000 \\
\hline & Body mass index & -0.015 & 0.004 & -0.213 & -3.955 & 0.000 \\
\hline & Genotype & 0.063 & 0.023 & 0.149 & 2.796 & 0.006 \\
\hline \multirow[t]{4}{*}{ ApoB } & Body mass index & 0.009 & 0.003 & 0.185 & 3.341 & 0.001 \\
\hline & Diastolic blood pressure & 0.004 & 0.001 & 0.217 & 3.920 & 0.000 \\
\hline & Blood glucose level & 0.033 & 0.006 & 0.279 & 5.291 & 0.000 \\
\hline & Alcohol consumption & 0.035 & 0.013 & 0.142 & 2.647 & 0.009 \\
\hline \multirow[t]{3}{*}{ ApoA1/ApoB } & Alcohol consumption & 0.098 & 0.028 & 0.188 & 3.479 & 0.001 \\
\hline & Body mass index & -0.039 & 0.006 & -0.361 & -6.708 & 0.000 \\
\hline & Blood glucose level & -0.057 & 0.014 & -0.223 & -4.184 & 0.000 \\
\hline \multicolumn{7}{|l|}{ Female } \\
\hline \multirow[t]{2}{*}{ TC } & Body mass index & 0.061 & 0.019 & 0.174 & 3.285 & 0.001 \\
\hline & Age & 0.209 & 0.042 & 0.266 & 5.028 & 0.000 \\
\hline \multirow[t]{4}{*}{ TG } & Body mass index & 0.083 & 0.020 & 0.218 & 4.117 & 0.000 \\
\hline & Genotype & -0.184 & 0.083 & -0.118 & -2.228 & 0.027 \\
\hline & Blood glucose level & 0.135 & 0.037 & 0.190 & 3.620 & 0.000 \\
\hline & Diastolic blood pressure & 0.016 & 0.006 & 0.147 & 2.800 & 0.005 \\
\hline \multirow[t]{3}{*}{ LDL-C } & Body mass index & 0.062 & 0.016 & 0.205 & 3.859 & 0.000 \\
\hline & Age & 0.204 & 0.036 & 0.303 & 5.725 & 0.000 \\
\hline & Alcohol consumption & -0.533 & 0.199 & -0.144 & -2.675 & 0.008 \\
\hline ApoA1 & Genotype & -0.047 & 0.019 & -0.136 & -2.471 & 0.014 \\
\hline \multirow[t]{3}{*}{ ApoA1/ApoB } & Alcohol consumption & 0.305 & 0.107 & 0.153 & 2.851 & 0.005 \\
\hline & Body mass index & -0.047 & 0.009 & -0.292 & -5.510 & 0.000 \\
\hline & Age & -0.082 & 0.019 & -0.227 & -4.287 & 0.000 \\
\hline
\end{tabular}

TC, total cholesterol; TG, triglyceride; HDL-C, high-density lipoprotein cholesterol; LDL-C, low-density lipoprotein cholesterol; ApoA1, apolipoprotein A1; ApoB, apolipoprotein B.

[15] found that the A allele was associated with increased levels of TG and LDL-C and decreased levels of HDL-C in European Ancestry. Tai et al. [24] also reported that the A allele was associated with increased levels of TC and LDL$\mathrm{C}$ but not with HDL-C in Malay population. Besides, Tai et al. [24] and Willer et al. [17] stated that the presence of 
rs17321515 SNP was also associated with an increased risk for prevalent CAD (OR 1.23 for each copy of the A allele). Recently, Nakayama et al. [41] showed that rs17321515 SNP was associated with serum TG $(3.5 \mathrm{mg} / \mathrm{dL}$ decrease per minor A allele) and LDL-C levels $(1.7 \mathrm{mg} / \mathrm{dL}$ decrease per minor A allele) in Japanese population. The Spanish familial hypercholesterolemic cohort study concluded that homozygous for A allels in smoker displayed higher plasma TG, higher VLDL-C concentrations and higher TC/HDL-C ratio than carriers of the minor allele $G$ and homozygous AA with the persence of arcus cornealis displayed lower plasma ApoA1 levels and higher TC/HDL-C than AG/GG subjects [39]. A recent study in Korean population also showed rs17321515 SNP was associated with increased serum levels of TG, LDL-C and HDL-C [42]. In the present study, we also found that the levels of HDL-C and LDL-C in Han were different among the AA, AG and GG genotypes, the subjects with AG/GG genotypes had higher serum HDL-C and LDL-C levels than the subjects with AA genotype. The levels of TC, HDL-C, LDL-C, ApoA1 and ApoB in Han males were different among the three genotypes, the $\mathrm{G}$ carriers had higher serum TC, HDL-C, LDL-C, ApoA1 and ApoB levels than the $\mathrm{G}$ noncarriers. The levels of HDL-C in Mulao males were different among the three genotypes, the $\mathrm{G}$ carriers had lower serum HDL-C levels than the G noncarriers. Therefore, the effects of rs17321515 SNP on serum lipid levels might be different between genders although it was not relevant in other studies. Another fact was the mean age of our study populaiton was higher than the other studies. In additions, different environmental and genetic factors might also contribute to variable levels of association with serum lipid levels in different populations.

It is well known that environmental factors such as dietary patterns, lifestyle, obesity, physical activity, and hypertension are all strongly related with serum lipid levels $[8,9]$. In the present study, we also showed that serum lipid parameters were correlated with age, sex, alcohol consumption, cigarette smoking, BMI, fasting blood glucose levels, and blood pressure in both ethnic groups. These data suggested that the environmental factors also played an important role in determining serum lipid levels in our populations. Although rice and corn are the staple foods in both ethnic groups, Mulao people prefer to eat cold foods along with acidic and spicy dishes, so bean soy sauce and pickled vegetables are among their most popular dishes. They also favor to eat animal offals which contain abundant saturated fatty acid. It has been widely accepted that high-fat diets, particularly those containing large quantities of saturated fatty acids raise blood cholesterol concentrations and predispose individuals to CAD [43]. Many studies also stated that diatery habits can impart a strong influence on serum levels of ApoB, ApoA1 and their ratio, and which in turn can effect the risk of CAD [44-46]. In the current study, we found that the levels of ApoB was higher in Mulao than in Han. This might be partly due to the difference in dietary habit between the Mulao and Han populations.

\section{Conclusion}

The present study showed that the genotypic and allelic frequencies of TRIB1 rs17321515 SNP were not different between the Mulao and Han populations, but the genotypic frequecies were different between Han males and females. The subjects with AG/GG genotypes in Han had higher serum HDL-C and LDL-C levels than the subjects with AA genotype. The G carriers in Han males had higher serum TC, HDL-C, LDL-C, ApoA1 and ApoB levels than the G noncarriers, but the G carriers in Mulao males had lower serum HDL-C levels than the $\mathrm{G}$ noncarriers. These differences in the association of TRIB1 rs17321515 SNP and serum lipid profiles between the two ethnic groups might partly result from different TRIB1 gene-enviromental interactions.

\section{Acknowledgements}

This study was supported by the National Natural Science Foundation of China (No: 30960130)

\section{Author details}

'Department of Cardiology, Institute of Cardiovascular Diseases, the First Affiliated Hospital, Guangxi Medical University, 22 Shuangyong Road, Nanning 530021, Guangxi, People's Republic of China. ${ }^{2}$ College of Stomatology, Guangxi Medical University, 10 Shuangyong Road, Nanning 530021, Guangxi, People's Republic of China. ${ }^{3}$ Clinical Laboratory of the Affiliated Cancer Hospital, Guangxi Medical University, 71 Hedi Road, Nanning 530021, People's Republic of China. ${ }^{4}$ The Center for Disease Control and Prevention of Luocheng Mulao Autonomous County, Luocheng 546400, Hechi, Guangxi, People's Republic of China. ${ }^{5}$ Department of Molecular Biology, Medical Scientific Research Center, Guangxi Medical University, 22 Shuangyong Road, Nanning 530021, Guangxi, People's Republic of China.

\section{Authors' contributions}

LHHA participated in the design, undertook genotyping, carried out the epidemiological survey, and drafted the manuscript. RXY conceived the study, participated in the design, carried out the epidemiological survey, collected the samples, and helped to draft the manuscript. DFW, QL and TTY collaborated to the genotyping. DFW, YMW, HL, DXW, YLS and DZY carried out the epidemiological survey and collected the samples. All authors read and approved the final manuscript.

\section{Competing interests}

The authors declare that they have no competing interests.

Received: 30 October 2011 Accepted: 6 December 2011 Published: 6 December 2011

\section{References}

1. Shekelle RB, Shryock AM, Paul O, Lepper M, Stamler J, Liu S, Raynor WJ Jr: Diet, serum cholesterol, and death from coronary heart disease. The Western Electric study. N Engl J Med 1981, 304:65-70.

2. Austin MA: Plasma triglyceride as a risk factor for coronary heart disease. The epidemiologic evidence and beyond. Am J Epidemiol 1989, 129:249-59.

3. Marz W, Scharnagl H, Winkler K, Tiran A, Nauck M, Boehm BO, Winkelmann BR: Low-density lipoprotein triglycerides associated with 
low-grade systemic inflammation, adhesion molecules, and angiographic coronary artery disease: the Ludwigshafen Risk and Cardiovascular Health study. Circulation 2004, 110:3068-74.

4. Kwiterovich PO Jr, Coresh J, Smith HH, Bachorik PS, Derby CA, Pearson TA: Comparison of the plasma levels of apolipoproteins $B$ and $A-1$, and other risk factors in men and women with premature coronary artery disease. Am J Cardiol 1992, 69:1015-21.

5. Boden WE: High-density lipoprotein cholesterol as an independent risk factor in cardiovascular disease: assessing the data from Framingham to the Veterans Affairs High-Density Lipoprotein Intervention Trial. Am J Cardiol 2000, 86:19L-22L.

6. Third Report of the National Cholesterol Education Program (NCEP) Expert Panel on Detection, Evaluation, and Treatment of High Blood Cholesterol in Adults (Adult Treatment Panel III) final report. Circulation 2002, 106:3143-421.

7. Teslovich TM, Musunuru K, Smith AV, Edmondson AC, Stylianou IM, Koseki M, Pirruccello JP, Ripatti S, Chasman DI, Willer CJ, Johansen CT, Fouchier SW, Isaacs A, Peloso GM, Barbalic M, Ricketts SL, Bis JC, Aulchenko YS, Thorleifsson G, Feitosa MF, Chambers J, Orho-Melander M, Melander O, Johnson T, Li X, Guo X, Li M, Shin Cho Y, Jin Go M, Jin Kim Y, et al: Biological, clinical and population relevance of 95 loci for blood lipids. Nature 2010, 466:707-13.

8. Ruixing $Y$, Fengping $H$, Shangling P, Dezhai $Y$, Weixiong $L$, Tangwei $L$, Yuming $C$, Jinzhen W, Limei $Y$, Jiandong H: Prevalence of hyperlipidemia and its risk factors for the middle-aged and elderly in the Guangxi Hei Yi Zhuang and Han populations. J Investig Med 2006, 54:191-200.

9. Ruixing Y, Qiming F, Dezhai Y, Shuquan L, Weixiong L, Shangling P, Hai W, Yongzhong Y, Feng H, Shuming Q: Comparison of demography, diet, lifestyle, and serum lipid levels between the Guangxi Bai Ku Yao and Han populations. J Lipid Res 2007, 48:2673-81.

10. Ruixing Y, Yiyang L, Meng L, Kela L, Xingjiang L, Lin Z, Wanying L, Jinzhen W, Dezhai $Y$, Weixiong L: Interactions of the apolipoprotein C-III $3238 \mathrm{C}>\mathrm{G}$ polymorphism and alcohol consumption on serum triglyceride levels. Lipids Health Dis 2010, 9:86.

11. Yin RX, Li YY, Liu WY, Zhang L, Wu JZ: Interactions of the apolipoprotein A5 gene polymorphisms and alcohol consumption on serum lipid levels. PLoS One 2011, 6:e17954.

12. Heller DA, de Faire U, Pedersen NL, Dahlen G, McClearn GE: Genetic and environmental influences on serum lipid levels in twins. N Engl J Med 1993, 328:1150-6.

13. Steinmetz J, Boerwinkle E, Gueguen R, Visvikis S, Henny J, Siest G: Multivariate genetic analysis of high density lipoprotein particles. Atherosclerosis 1992, 92:219-27.

14. Perusse L, Rice T, Despres JP, Bergeron J, Province MA, Gagnon J, Leon AS, Rao DC, Skinner JS, Wilmore JH, Bouchard C: Familial resemblance of plasma lipids, lipoproteins and postheparin lipoprotein and hepatic lipases in the HERITAGE Family Study. Arterioscler Thromb Vasc Biol 1997, 17:3263-9

15. Kathiresan S, Melander O, Guiducci C, Surti A, Burtt NP, Rieder MJ, Cooper GM, Roos C, Voight BF, Havulinna AS, Wahlstrand B, Hedner T, Corella D, Tai ES, Ordovas JM, Berglund G, Vartiainen E, Jousilahti P, Hedblad B, Taskinen MR, Newton-Cheh C, Salomaa V, Peltonen L, Groop L, Altshuler DM, Orho-Melander M: Six new loci associated with blood lowdensity lipoprotein cholesterol, high-density lipoprotein cholesterol or triglycerides in humans. Nat Genet 2008, 40:189-97.

16. Sandhu MS, Waterworth DM, Debenham SL, Wheeler E, Papadakis K, Zhao JH, Song K, Yuan X, Johnson T, Ashford S, Inouye M, Luben R, Sims M, Hadley D, McArdle W, Barter P, Kesäniemi YA, Mahley RW, McPherson R, Grundy SM, Bingham SA, Khaw KT, Loos RJ, Waeber G, Barroso I, Strachan DP, Deloukas P, Vollenweider P, Wareham NJ, Mooser V: LDLcholesterol concentrations: a genome-wide association study. Lancet 2008, 371:483-91.

17. Willer CJ, Sanna S, Jackson AU, Scuteri A, Bonnycastle LL, Clarke R, Heath SC, Timpson NJ, Najjar SS, Stringham HM, Strait J, Duren WL, Maschio A, Busonero F, Mulas A, Albai G, Swift AJ, Morken MA, Narisu N, Bennett D, Parish S, Shen H, Galan P, Meneton P, Hercberg S, Zelenika D, Chen WM, Li Y, Scott LJ, Scheet PA, et al: Newly identified loci that influence lipid concentrations and risk of coronary artery disease. Nat Genet 2008, 40:161-9.

18. Sung HY, Guan H, Czibula A, King AR, Eder K, Heath E, Suvarna SK, Dower SK, Wilson AG, Francis SE, Crossman DC, Kiss-Toth E: Human tribbles-1 controls proliferation and chemotaxis of smooth muscle cells via MAPK signaling pathways. J Biol Chem 2007, 282:18379-18387.

19. Hegedus Z, Czibula A, Kiss-Toth E: Tribbles: a family of kinase-like proteins with potent signalling regulatory function. Cell Signal 2007, 19:238-50.

20. Sung HY, Francis SE, Crossman DC, Kiss-Toth E: Regulation of expression and signalling modulator function of mammalian tribbles is cell-type specific. Immunol Lett 2006, 104:171-7.

21. Kathiresan S, Willer CJ, Peloso GM, Demissie S, Musunuru K, Schadt EE, Kaplan L, Bennett D, Li Y, Tanaka T, Voight BF, Bonnycastle LL, Jackson AU, Crawford G, Surti A, Guiducci C, Burtt NP, Parish S, Clarke R, Zelenika D, Kubalanza KA, Morken MA, Scott LJ, Stringham HM, Galan P, Swift AJ, Kuusisto J, Bergman RN, Sundvall J, Laakso M, et al: Common variants at 30 loci contribute to polygenic dyslipidemia. Nat Genet 2009, 41:56-65.

22. Kiss-Toth E, Bagstaff SM, Sung HY, Jozsa V, Dempsey C, Caunt JC, Oxley KM, Wyllie DH, Polgar T, Harte M, O'neill LA, Qwarnstrom EE, Dower SK: Human tribbles, a protein family controlling mitogen-activated protein kinase cascades. J Biol Chem 2004, 279:42703-8.

23. Burkhardt R, Toh SA, Lagor WR, Birkeland A, Levin M, Li X, Robblee M, Fedorov VD, Yamamoto M, Satoh T, Akira S, Kathiresan S, Breslow JL, Rader DJ: Trib1 is a lipid- and myocardial infarction-associated gene that regulates hepatic lipogenesis and VLDL production in mice. J Clin Invest 2010, 120:4410-4.

24. Tai ES, Sim XL, Ong TH, Wong TY, Saw SM, Aung T, Kathiresan S, OrhoMelander M, Ordovas JM, Tan JT, Seielstad M: Polymorphisms at newly identified lipid-associated loci are associated with blood lipids and cardiovascular disease in an Asian Malay population. J Lipid Res 2009, 50:514-20.

25. Wang J, Ban MR, Zou GY, Cao H, Lin T, Kennedy BA, Anand S, Yusuf S, Huff MW, Pollex RL, Hegele RA: Polygenic determinants of severe hypertriglyceridemia. Hum Mol Genet 2008, 17:2894-9.

26. Xu L, Deng QY, Li SF, Zhou LN, Gong JC, Wei BY: Genetic analysis of Mulao nationality using 15 short tandem repeats. Zhonghua $Y_{i} X_{u} Y_{i}$ Chuan Xue Za Zhi 2008, 25:96-100.

27. Li Q, Yin RX, Yan TT, Miao L, Cao XL, Hu XJ, Aung LH, Wu DF, Wu JZ, Lin WX: Association of the GALNT2 gene polymorphisms and several environmental factors with serum lipid levels in the Mulao and Han populations. Lipids Health Dis 2011, 10:160.

28. An epidemiological study of cardiovascular and cardiopulmonary disease risk factors in four populations in the People's Republic of China. Baseline report from the P.R.C.-U.S.A. Collaborative Study. People's Republic of China-United States Cardiovascular and Cardiopulmonary Epidemiology Research Group. Circulation 1992, 85:1083-96.

29. Ruixing $Y$, Yuming $C$, Shangling P, Fengping $H$, Tangwei L, Dezhai $Y$, Jinzhen $W$, Limei $Y$, Weixiong $L$, Rongshan $L$, Jiandong $H$ : Effects of demographic, dietary and other lifestyle factors on the prevalence of hyperlipidemia in Guangxi Hei Yi Zhuang and Han populations. Eur $J$ Cardiovasc Prev Rehabil 2006, 13:977-84.

30. Ruixing $Y$, Jinzhen $W$, Yaoheng $H$, Jing $T$, Hai W, Muyan L, Yiyang $L$, Dongmei F, Hanjun Y, Yuming C: Associations of diet and lifestyle with hyperlipidemia for middle-aged and elderly persons among the Guangxi Bai Ku Yao and Han populations. J Am Diet Assoc 2008, 108:970-6.

31. Yijiang Z, Ruixing Y, Yiyang L, Yaju D, Shangling P, Weixiong L, Dezhai Y: Association of TaqIB polymorphism in the cholesteryl ester transfer protein gene with serum lipid levels in the Guangxi Hei Yi Zhuang and Han populations. J Investig Med 2008, 56:847-57.

32. Ruixing $Y$, Guangqin $C$, Yong W, Weixiong L, Dezhai Y, Shangling P: Effect of the $3^{\prime} A P O B-V N T R$ polymorphism on the lipid profiles in the Guangxi Hei Yi Zhuang and Han populations. BMC Med Genet 2007, 8:45.

33. Ruixing $Y$, Shangling $P$, Shuquan $L$, Dezhai $Y$, Weixiong $L$, Qiming F, Yuming C, Yaoheng H, Yijiang Z, Qinchen L: Comparison of hypertension and its risk factors between the Guangxi Bai Ku Yao and Han populations. Blood Press 2008, 17:306-16.

34. Ruixing Y, Weixiong L, Hanjun Y, Dezhai Y, Shuquan L, Shangling P, Qiming F, Jinzhen W, Jianting G, Yaju D: Diet, lifestyle, and blood pressure of the middle-aged and elderly in the Guangxi Bai Ku Yao and Han populations. Am J Hypertens 2008, 21:382-7.

35. Long XJ, Yin RX, Li KL, Liu WY, Zhang L, Cao XL, Miao L, Wu DF, Aung LH, Hu XJ: Low density lipoprotein receptor gene Ava II polymorphism and serum lipid levels in the Guangxi Bai Ku Yao and Han populations. Lipids Health Dis 2011, 10:34. 
36. Aung LH, Yin RX, Miao L, Hu XJ, Yan TT, Cao XL, Wu DF, Li Q, Pan SL, Wu JZ: The proprotein convertase subtilisin/kexin type 9 gene E670G polymorphism and serum lipid levels in the Guangxi Bai Ku Yao and Han populations. Lipids Health Dis 2011, 10:5.

37. Wu DF, Yin RX, Aung LH, Hu XJ, Cao XL, Miao L, Li Q, Yan TT, Wu JZ, Pan SL: Polymorphism of rs 1044925 in the acyl-CoA:cholesterol acyltransferase-1 gene and serum lipid levels in the Guangxi Bai Ku Yao and Han populations. Lipids Health Dis 2010, 9:139.

38. Cao XL, Yin RX, Wu DF, Miao L, Aung LH, Hu XJ, Li Q, Yan TT, Lin WX, Pan SL: Genetic variant of V825I in the ATP-binding cassette transporter A1 gene and serum lipid levels in the Guangxi Bai Ku Yao and Han populations. Lipids Health Dis 2011, 10:14.

39. Garcia-Rios A, Perez-Martinez P, Mata P, Fuentes F, Lopez-Miranda J, Alonso R, Caballero J, Mata N, Perez-Jimenez F, Ordovas JM: Polymorphism at the TRIB1 gene modulates plasma lipid levels: Insight from the spanish familial hypercholesterolemia cohort study. Nutr Metab Cardiovasc Dis .

40. Hegele RA, Ban MR, Hsueh N, Kennedy BA, Cao H, Zou GY, Anand S, Yusuf S, Huff MW, Wang J: A polygenic basis for four classical Fredrickson hyperlipoproteinemia phenotypes that are characterized by hypertriglyceridemia. Hum Mol Genet 2009, 18:4189-94.

41. Nakayama K, Bayasgalan T, Yamanaka K, Kumada M, Gotoh T, Utsumi N, Yanagisawa Y, Okayama M, Kajii E, Ishibashi S, Iwamoto S, Jichi Community Genetics Team (JCOG): Large scale replication analysis of loci associated with lipid concentrations in a Japanese population. J Med Genet 2009, 46:370-4.

42. Park MH, Kim N, Lee JY, Park HY: Genetic loci associated with lipid concentrations and cardiovascular risk factors in the Korean population. J Med Genet 2011, 48:10-5.

43. Yu-Poth S, Zhao G, Etherton T, Naglak M, Jonnalagadda S, Kris-Etherton PM: Effects of the National Cholesterol Education Program's Step I and Step II dietary intervention programs on cardiovascular disease risk factors: a meta-analysis. Am J Clin Nutr 1999, 69:632-46.

44. Sola R, Fito M, Estruch R, Salas-Salvado J, Corella D, de La Torre R, Munoz MA, Lopez-Sabater Mdel C, Martinez-Gonzalez MA, Aros F, et al: Effect of a traditional Mediterranean diet on apolipoproteins B, A-I, and their ratio: a randomized, controlled trial. Atherosclerosis 2011, 218:174-180.

45. Valente EA, Sheehy ME, Avila JJ, Gutierres JA, Delmonico MJ, Lofgren IE: The effect of the addition of resistance training to a dietary education intervention on apolipoproteins and diet quality in overweight and obese older adults. Clin Interv Aging 2011, 6:235-241.

46. Dominiczak MH, Caslake MJ: Apolipoproteins: metabolic role and clinical biochemistry applications. Ann Clin Biochem 2011.

\section{Submit your next manuscript to BioMed Central and take full advantage of:}

- Convenient online submission

- Thorough peer review

- No space constraints or color figure charges

- Immediate publication on acceptance

- Inclusion in PubMed, CAS, Scopus and Google Scholar

- Research which is freely available for redistribution 